\title{
EL ARCHIVO DIGITAL DEL ROMANCERO: OMEKA APLICADO A LA PRESERVACIÓN Y EL ANÁLISIS DE LA POESÍA TRADICIONAL
}

\author{
Nicolás Asensio Jiménez \\ Sara Sánchez Bellido \\ Fundación Ramón Menéndez Pidal \\ asensio.n@hotmail.com
}

\begin{abstract}
RESUMEN: El Archivo Digital del Romancero es el resultado del proyecto de digitalización de los fondos de poesía tradicional de la Fundación Ramón Menéndez Pidal. Se trata de un repositorio virtual creado mediante el software Omeka e ideado con dos objetivos fundamentales: la preservación de un patrimonio único y la difusión de sus contenidos para que puedan ser fruto de análisis por parte de la comunidad científica. Mediante este artículo nos proponemos trazar un recorrido por esta herramienta que no solo sirva como presentación sino también como una práctica demostración de su uso y posibilidades; pero, además, detallaremos los principales problemas a los que nos hemos enfrentado en el proceso de adaptar los documentos desde el formato analógico al digital con la modesta intención de que pueda servir de ayuda a investigadores que se encuentren en proyectos similares.

PALABRAS CLAVE: archivos digitales, romancero, poesía tradicional, Omeka, humanidades digitales.
\end{abstract}

\section{THE ROMANCERO DIGITAL ARCHIVE: OMEKA AS A TOOL FOR PRESERVING AND STUDYING TRADITIONAL POETRY}

\begin{abstract}
Ramon Menendez Pidal Foundation has been digitizing its documentary collection of Spanish traditional ballads since December of 2013. As a result, it has been recently created the Romancero Digital Archive, a website designed by Omeka with the aim of preserving this cultural heritage as well as making it public among the academic community. The purpose of this paper is to make a complete introduction to this tool by showing its posibilities for traditional poetry research. Besides, it describes the principal problems we faced through the process of adapting the documents from analogic format to digital format in hopes that it could be useful for scholars who are developing similar projects.

KEYWORDS: digital archives, romancero, traditional ballads, Omeka, digital humanities.
\end{abstract}

Recibido: 25/02/2016. Aceptado: 12/09/2016 
El Archivo del Romancero de la Fundación Ramón Menéndez Pidal es, sin duda, la mayor colección documental de baladas hispánicas existente en el mundo ${ }^{1}$. Se trata de un proyecto que inició el mismo don Ramón junto a María Goyri, su mujer, a principios del siglo XX y que se ha ido enriqueciendo con la labor de numerosos intelectuales a lo largo del tiempo². En la histórica casa de estos intelectuales en Madrid, en una sala de a penas once metros cuadrados con trece archivadores se custodian miles de documentos relacionados con cientos de romances transmitidos en español, catalán, gallego, judeoespañol y portugués (Figuras 1 y 2); sus formatos y soportes son realmente diversos, ya que podemos encontrar, entre otros, reproducciones de manuscritos medievales y pliegos sueltos e impresos del Siglo de Oro, notas de campo de folkloristas, manuscritos originales de Menéndez Pidal, Lorca, Unamuno, Tomás Navarro Tomás con versiones o estudios de distintos romances y, también, una gran colección de documentos sonoros de las encuestas realizadas en las décadas de los ochenta y noventa (Figura 3).

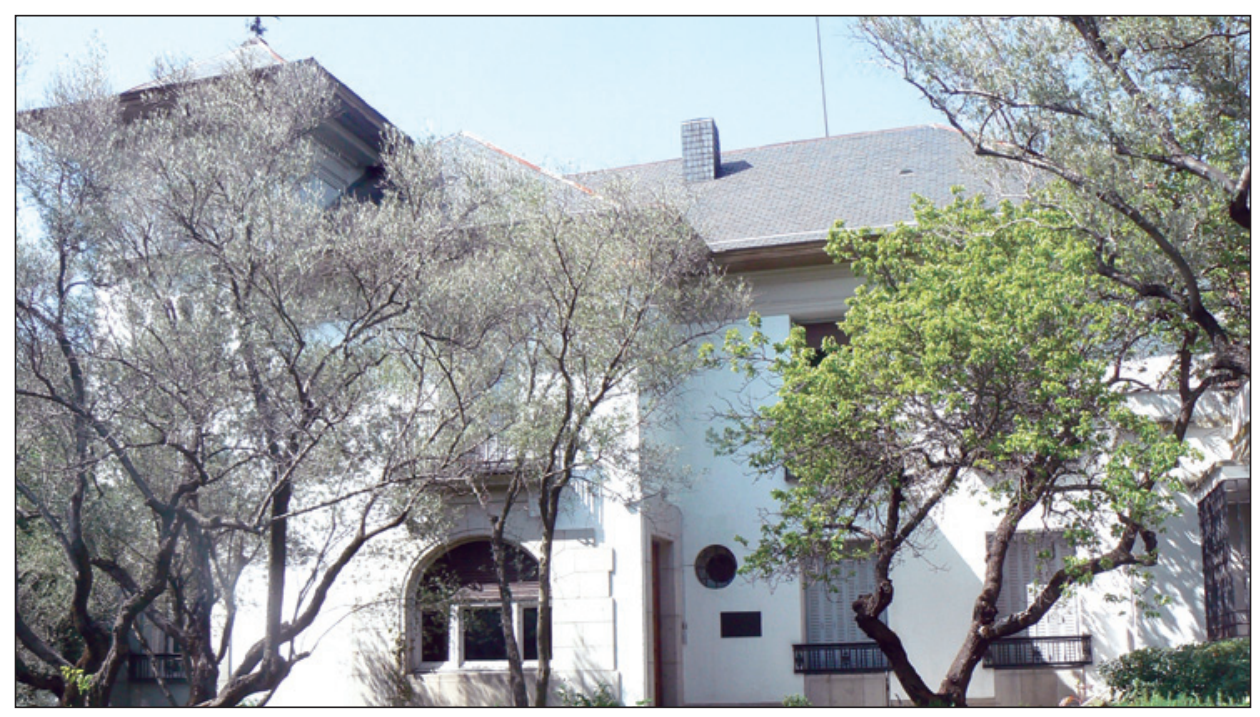

Figura 1. Sede de la Fundación Ramón Menéndez Pidal en la histórica casa de Chamartín donde se custodia el Archivo del Romancero.

1. Este artículo se enmarca dentro del proyecto de investigación FFI2014-54368-P “Catalogación, Digitalización y Edición del Romancero Tradicional de las Lenguas Hispánicas: Romances épicos e históricos de referente hispánico y francés” del Ministerio de Economía y Competitividad.

2. Para más información sobre la historia del Archivo de la Fundación Ramón Menéndez Pidal, consúltese la gran obra de Diego Catalán (2001). 


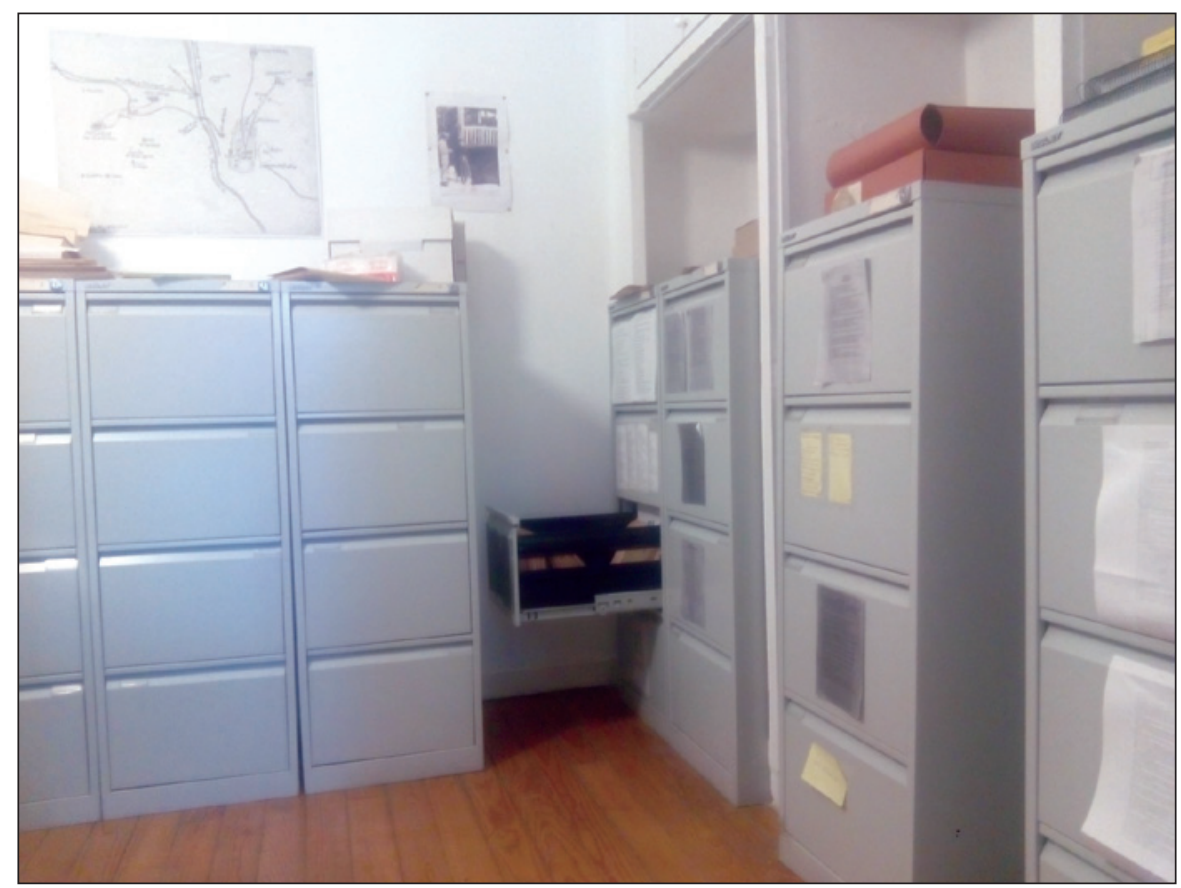

Figura 2. Principal sala del Archivo del Romancero.

A pesar de que la imagen que podemos tener de un archivo documental sea una entidad sólida e inamovible que atesora el patrimonio de épocas pasadas, lo cierto es que está en continuo movimiento, adaptándose y moldeándose a las necesidades de cada tiempo. Por un lado, debido a su carácter de preservador de la cultura, el archivo vive en una constante actualización al incorporar con frecuencia nuevos testimonios que aportan considerable riqueza al conjunto de materiales custodiados y, también, debe conocer y utilizar los últimos métodos que aseguren la protección de sus fondos. Por otro lado, el archivo debe ser una herramienta de acceso al patrimonio conservado, por lo que es necesario que se adecúe a las exigencias del público investigador en cada momento ${ }^{3}$.

3. Al respecto de estas reflexiones, un buen estudio que arroja luz sobre las problemáticas de los archivos con mayor claridad y precisión es el de Heredia Herrera (2007), donde hace especial hincapié en la dicotomía del archivo como institución y como contenido documental. 


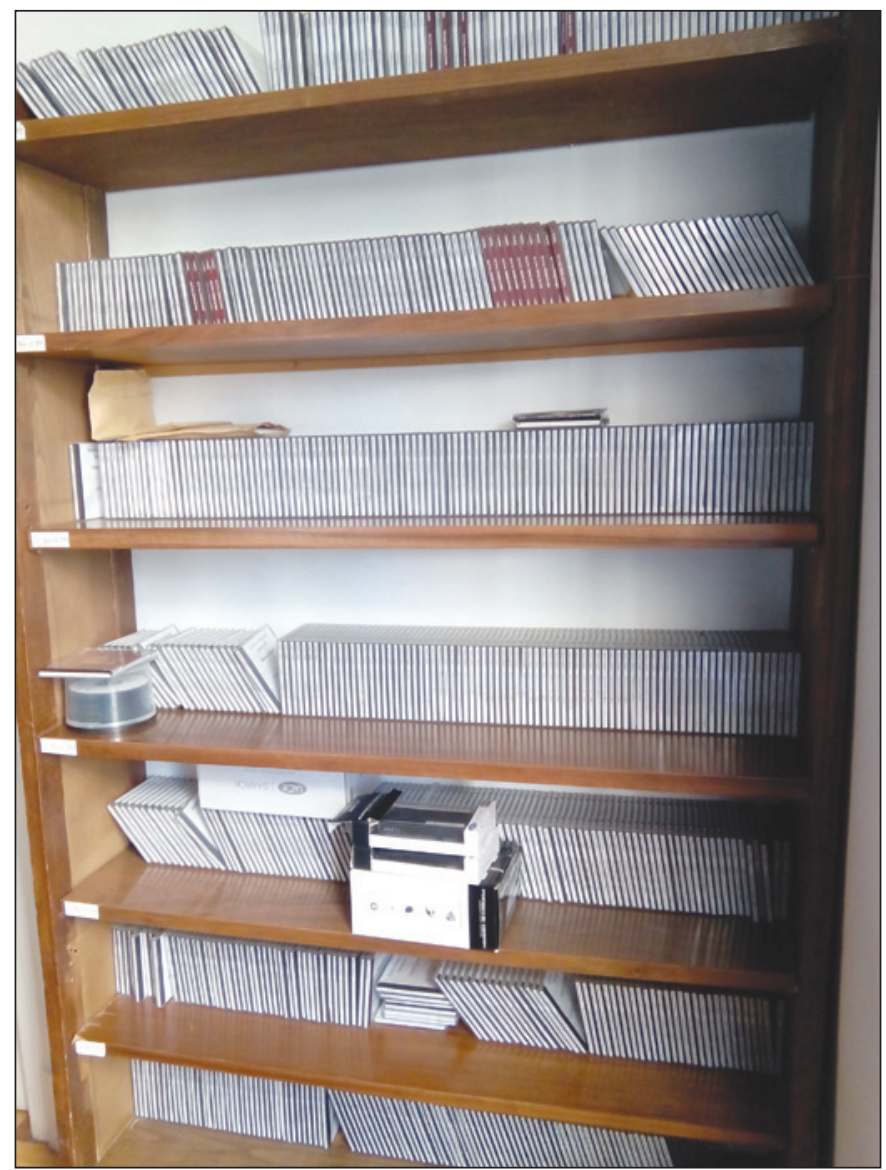

Figura 3. Archivo Sonoro del Romancero.

Cuando Menéndez Pidal comenzó a reunir de forma sistemática todos sus documentos sobre el romancero, lo concibió como un proyecto personal que ayudaría a sus propios trabajos. No obstante, al ir recibiendo periódicamente numerosas aportaciones de colaboradores, el proyecto tomó unas dimensiones más amplias y fueron necesarios esfuerzos de organización de los documentos en torno a corpus temáticos y, también, unas incipientes labores catalogación a través de signaturas. Debido a que aumentaron las peticiones de consulta por parte de investigadores e, incluso, un equipo de filólogos trabajaba de forma directa con estos documentos para su edición, fue necesario un proyecto de catalogación mayor, a largo plazo, que ordenara de forma más precisa los documentos y deta- 
llara la información más relevante de cada uno de ellos. Así, nació la primera parte del Catálogo Analítico del Archivo Romancístico Menéndez Pidal - Goyri (Catalán 1998), que abarca los romances épicos e históricos de referente hispánico. Fue una obra en la que trabajó durante años un equipo de cinco investigadores dirigidos por Diego Catalán y que formalizó las líneas a seguir en las futuras labores; de hecho, en las actuales tareas de catalogación se sigue el mismo modelo. Sin embargo, este Catálogo Analítico solo abarca, aproximadamente, una quinta parte de los fondos del Archivo; por ello, los últimos proyectos de la Fundación Ramón Menéndez Pidal dan prioridad a la catalogación del resto de documentos al mismo tiempo que promueven su digitalización, pues es necesario que el Archivo se adapte al nuevo paradigma de mundo digital en que vivimos.

De este modo, dos son las principales razones por las que desde diciembre del año 2013 se ha iniciado el proyecto de digitalización del Archivo del Romancero. La primera es asegurar de forma inmediata la preservación de sus fondos, pues sus soportes materiales -papel, cintas magnéticas y discos electrónicos, esencialmente- son de gran vulnerabilidad ante cualquier incidencia o ante el mismo paso de los años. La segunda razón es favorecer la difusión y la consulta de este patrimonio, debido a que es desconocido en gran parte por el público general. Desde el inicio del proyecto hasta este momento -y gracias a las ayudas de ciertas instituciones ${ }^{4}$-, se ha digitalizado aproximadamente un $30 \%$ de los fondos, han continuado las labores de catalogación para facilitar futuras digitalizaciones y se ha puesto a disposición del público la primera colección del Archivo en la siguiente dirección web: www.fundacionramonmenendezpidal.org/ archivodigital, que vamos a dar a conocer con mayor precisión a continuación.

Para la creación del Archivo Digital ${ }^{5}$ elegimos la herramienta Omeka ${ }^{6}$. Se trata de un software libre de gestión de contenidos digitales muy popular ya en otras bibliotecas, archivos e instituciones ${ }^{7}$. La principal ventaja que ofrece concre-

4. Concretamente, agradecemos la colaboración en distintas fases del proyecto de las siguientes instituciones, sin las cuales no habría sido posible: Universidad Complutense de Madrid, Fundación Juan Entrecanales de Azcárate y Ministerio de Economía y Competitividad de España.

5. Huelga decir que el término archivo digital es el que mejor se ajustaba a nuestro proyecto por ser, como sugiere el nombre, el ajuste de los fondos del formato analógico al digital. No queremos entrar en la problemática de la nomenclatura electrónica que señala Lucía Megías (2010).

6. El software, junto a utilísima información, puede explorarse a través del siguiente enlace: http:// omeka.org/. Asimismo, una buena introducción y guía a esta aplicación se encuentra en el artículo de Kucsma et al. (2010).

7. Véanse, por ejemplo, el Hurricane Digital Memory Bank del Roy Rosenzweig Center for History and New Media (CHNM) de la Universidad George Mason y la Universidad de Nueva Orleans: http:// www.hurricanearchive.org; o las colecciones de la Cambridge Digital Library: http://cudl.lib.cam.ac.uk/. 
tamente al proyecto de digitalización del Archivo el Romancero es la adaptación viable de las labores de catalogación previas, en especial del Catálogo Analítico. Por una parte, la organización en colecciones de los elementos digitales tiene cierta semejanza con la estructuración en grupos temáticos de los documentos del Archivo en este catálogo. Por otra parte, el patrón Dublin Core que siguen los metadatos de este software se ajusta con relativa facilidad a la información precisa de cada documento del Archivo, como veremos con detalle más adelante ${ }^{8}$.

Antes de conocer las partes del Archivo Digital, debemos señalar que al abrir la dirección web que lo contiene, se requiere una identificación mediante usuario y contraseña (Figura 4). Un nuevo usuario no encontrará ninguna dificultad al seguir los pasos necesarios para registrarse: basta con situarse en la parte superior derecha, pulsar sobre la opción "Registrarse” y rellenar el formulario que se abre en la nueva ventana. Una vez hecho esto, se debe esperar un breve tiempo a que el usuario sea activado por parte de la Fundación Ramón Menéndez Pidal; le llegará, entonces, un correo electrónico de confirmación y podrá acceder al Archivo Digital.

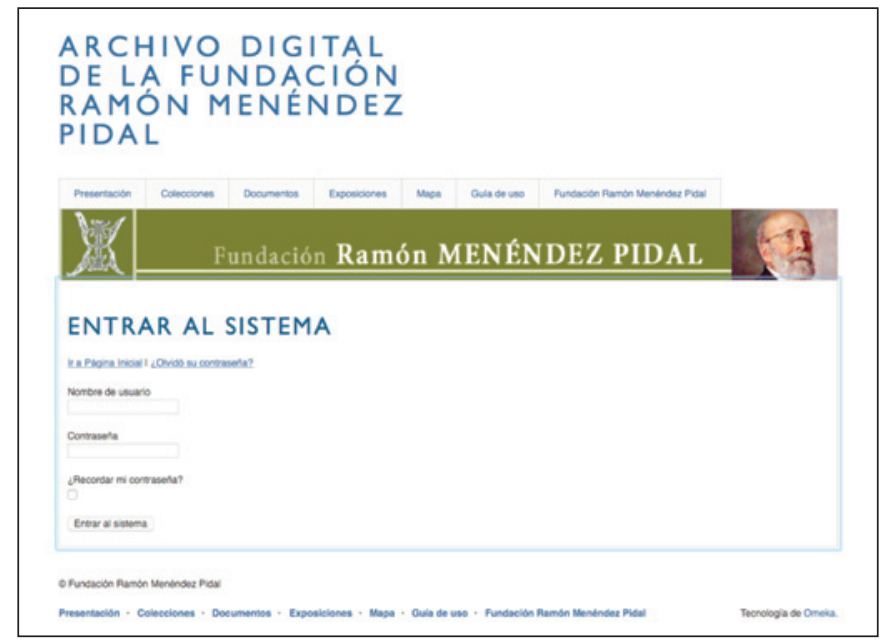

Figura 4. Registro y acceso al Archivo Digital del Romancero.

8. En efecto, quizá la mayor ventaja de los campos de metadatos de Dublin Core es su versatilidad, la cual permite adaptar información de documentos muy distintos bajo un etiquetado común. En palabras de Wagner y Weibel (2005: 2): "the registry is intended to serve as a discovery mechanism and resolution service, with the goal of promoting the reuse of existing terminologies represented in multiple languages." Para más información sobre este estándar de codificación, véase Daudinot Founier (2006) y Weibel (2010). 
Una vez hayamos accedido, podremos observar una interfaz sencilla y funcional (Figura 5). La página principal que se abre por defecto muestra una pequeña descripción del Archivo Digital, un elemento destacado, una colección destacada y los elementos añadidos recientemente. En la parte superior, bajo el logotipo de la Fundación, encontramos un menú compuesto por ocho pestañas. La pestaña "Presentación" da una breve nota introductoria a la historia y los objetivos del Archivo; la pestaña "Colecciones" abre un submenú donde se despliegan las diferentes secciones temáticas; la pestaña "Documentos" permite la visualización y búsqueda de los elementos así como la navegación por etiquetas y la exploración del mapa geográfico; la pestaña "Exposiciones" muestra las diferentes exhibiciones temáticas que se crean con carácter temporal; la pestaña "Mapa" facilita la localización geográfica de los documentos; la pestaña “Fundación Ramón Menéndez Pidal” conduce directamente al sitio web de esta institución; la pestaña “Guía de uso” proporciona unas sencillas instrucciones para manejar con desenvoltura el Archivo Digital y señala los términos legales de reproducción y publicación de imágenes; y, finalmente, la pestaña "Scripto" conduce a un plugin de transcripción de textos del que hablaremos más adelante.

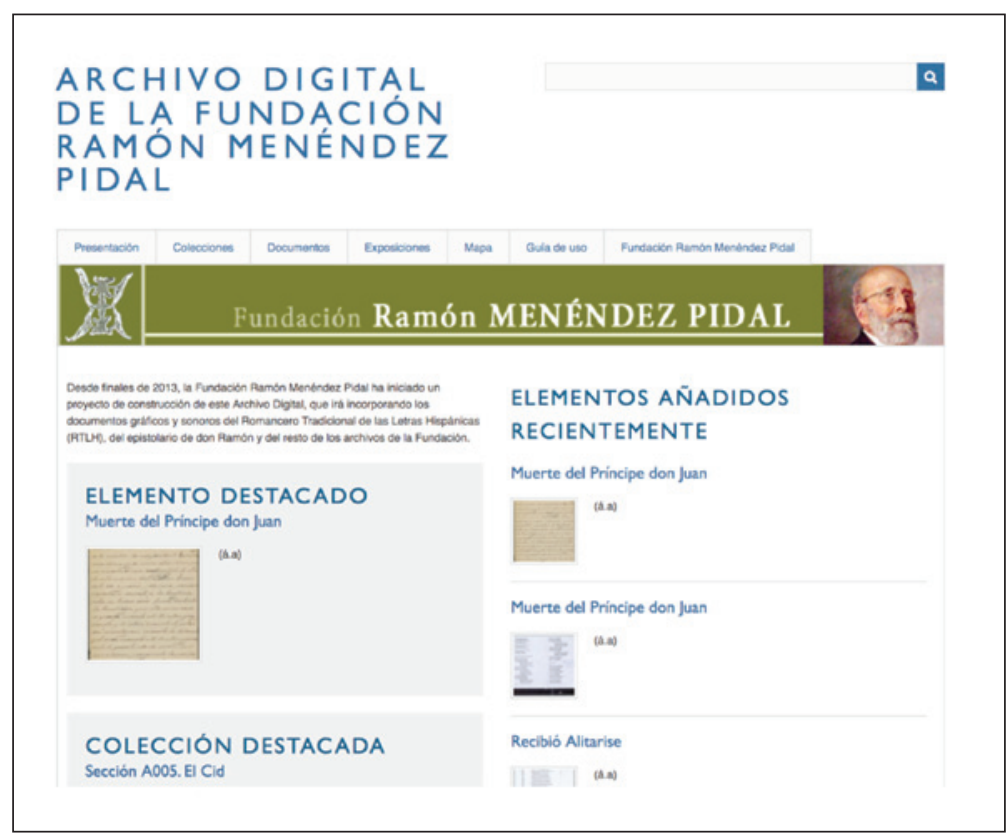

Figura 5. Interfaz y página principal del Archivo Digital del Romancero. 
La primera colección recientemente migrada se trata de los romances épicos e históricos de referente hispánico. Están distribuidos en dieciséis secciones temáticas que se pueden observar en el menú de "Colecciones" (Figura 6): 0) Ensaladas, 1) Bernardo del Carpio, 2) Fernán González, 3) Los infantes de Lara, 4) Infante García e hijos de Sancho el Mayor, 5) El Cid, 6) Temas históricolegendarios hasta el fin de la Dinastía Leonesa, 7) Temas histórico-legendarios desde Fernando I a Sancho IV, 8) Romances noticieros o de tema histórico anterior a los Trastámara, 9) Romances noticieros o de tema histórico de tiempo de los Trastámara, 10) Romances noticieros o de tema histórico de tiempo de los Reyes Católicos, 11) Romances moriscos, 12) Romances noticieros de tiempo de los Austrias, 13) Romances sobre la conquista de América, 14) Historia moderna y 15) Otros romances de tema histórico nacional. En total, suman alrededor de doce mil (12.000) elementos, todos ellos imágenes con metadatos, pues los documentos audiovisuales serán incorporados en las siguientes fases.
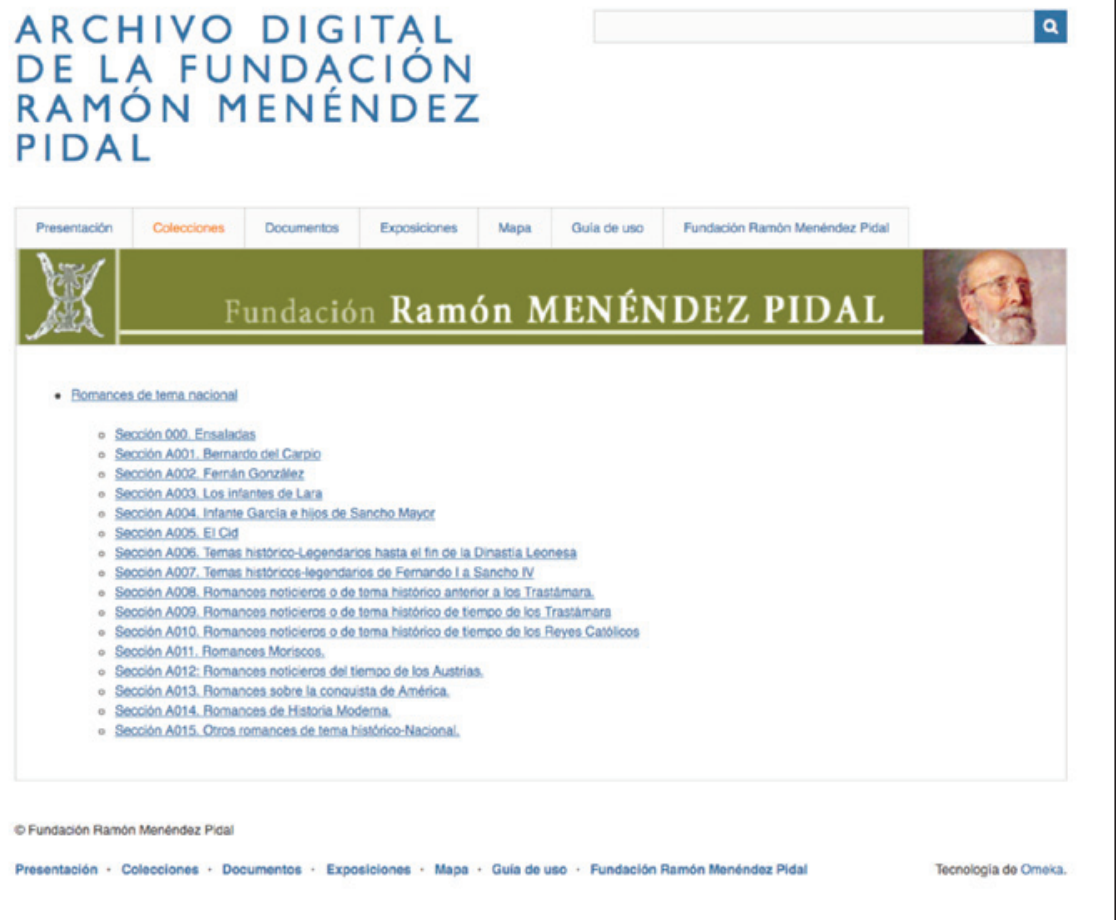

Figura 6. Colecciones migradas al Archivo Digital del Romancero. 
$\mathrm{Al}$ abrir cualquiera de estas secciones, se despliegan sus documentos distribuidos en distintas páginas que visualizan las miniaturas y los títulos de cada uno de ellos junto a la relación, descripción e identificador (signatura), concretamente en conjuntos de quince elementos (Figura 7). Puede sorprender, primero, que aparezca un mismo título repetido en multitud de ocasiones. Esto se debe a que el título de cada documento corresponde directamente con el título de cada romance al que pertenece, de tal modo que, por ejemplo, bajo el título "Jimena pide justicia” se agrupan tanto sus versiones antiguas del Siglo de Oro, sus versiones de la tradición oral moderna, sus citas y adaptaciones o los estudios principales que ha germinado; para obtener información más precisa sobre cada documento es necesario abrirlo, como haremos un poco más adelante, pero esta forma de visualización facilita la consulta rápida por temas romancísticos, la cual es, sin duda, la más solicitada. Puede sorprender, también, que los documentos no estén organizados alfabéticamente, como es común en otros repositorios virtuales. Siguen, en efecto, la estructuración del Catálogo Analítico. Los documentos se ordenan de acuerdo a criterios temáticos y narrativos, como puede observarse con facilidad -siguiendo con el ejemplo- en la sección del Cid, la cual se inicia con los estudios generales, se continúa con los romances de las mocedades y se termina con los romances del destierro y madurez del héroe.

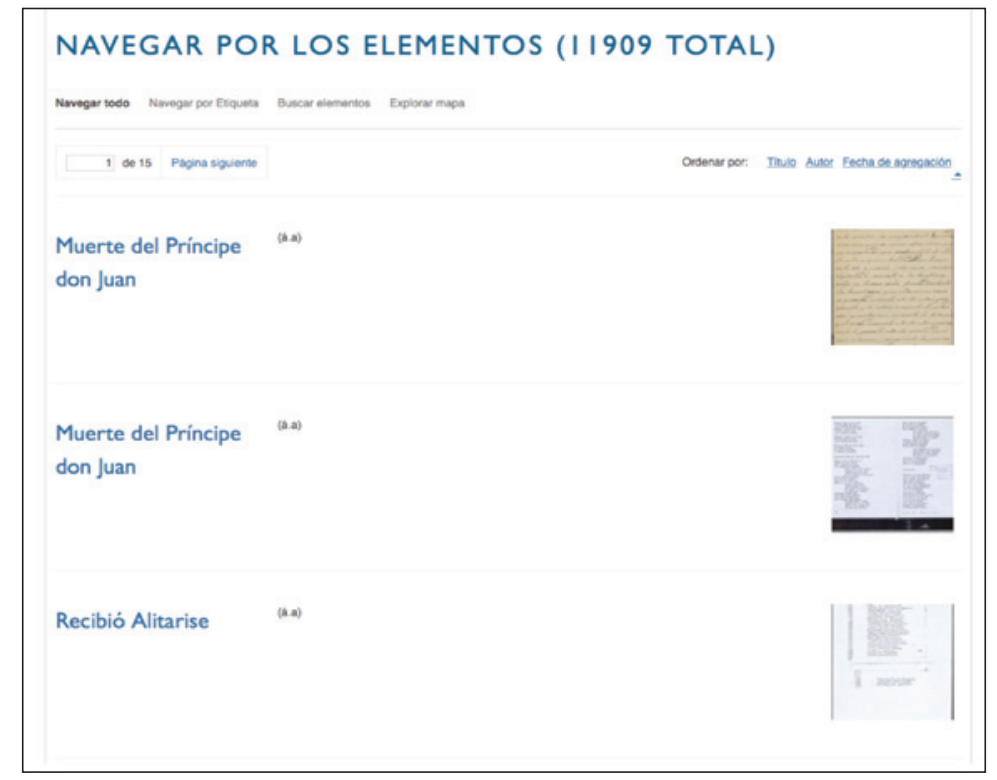

Figura 7. Elementos de la sección

"Romances noticieros de la época de los Reyes Católicos". 
Como acabo de comentar, para obtener información más precisa de cada documento debemos acceder a él. La información de cada elemento se agrupa entre ocho o diez campos diferentes de metadatos (Figura 8). Estos son: "Título", "Descripción”, “Idioma”, “Identificador”, “Fecha”, “Colaborador”, “Relación”, "Tipo" , "Cobertura” y "Archivos". El primero, como su nombre indica, contiene el título del romance al que pertenece el documento, salvo en casos muy particulares que no hagan referencia a un romance concreto como "Estudios generales sobre los romances del Cid”. El segundo campo proporciona una descripción de la naturaleza del documento, concretamente pueden ser los siguientes tipos de

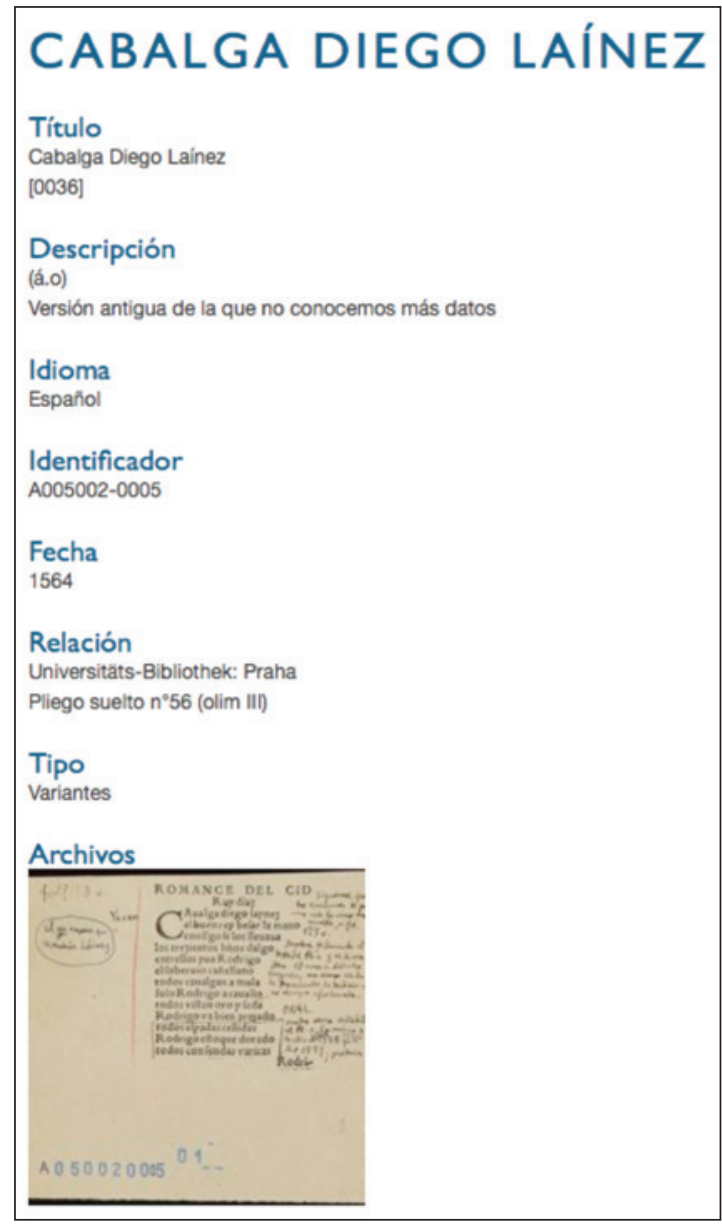

Figura 8. Campos de metadatos de un documento del Archivo del Romancero. 
información: versión antigua (con las subdivisones: sin más datos, manuscrita, manuscrita editada, impresa, reeditada), versión moderna (con las mismas subdivisiones), adaptación, cita o alusión, contrafactura, versión oral (con las subdivisiones: transcrita, primera impresión, reeditada, facticia), explicación de pormenores, paralelo, estudio, material de estudio, remisión interna, contaminación, fragmento, música, variantes y varios ${ }^{9}$. El tercer campo se trata del idioma en que está escrito el documento. El cuarto la signatura, que corresponde directamente con el Catálogo. El quinto es la fecha del documento original. El sexto muestra los colaboradores, normalmente, colectores y recitadores. El séptimo, bastante general, indica la naturaleza material de documento $\mathrm{y}$, generalmente, el lugar donde se conserva. El octavo indica el tipo de documento, si se trata de original, fotocopia, etc. El noveno muestra el lugar de procedencia. El décimo se trata de los archivos con las imágenes.

Pongamos un ejemplo preciso. Una versión moderna del romance "El rey moro que reta a Valencia”, por ejemplo ${ }^{10}$, presenta los siguientes campos de metadatos. El primer campo es el "Título", donde no solo aparece el título del romance sino también el IGR ${ }^{11}$ (0045). El segundo campo es la "Descripción”, en el que aparece la asonancia (á.a) y se especifica que se trata de una versión oral moderna. El tercer campo es el "Idioma”, donde se especifica la lengua del documento. El cuarto es el "Identificador”, es decir, la signatura del catálogo. El quinto campo es la "Fecha”, concretamente, el año en que fue recogido este romance. El sexto es el "Colaborador”, en este caso, el colector de la versión, José Benoliel. El séptimo campo es "Relación”, que especifica que se trata de un manuscrito. El octavo es el "Tipo", donde refiere que es un original. El noveno es la "Cobertura” o, mejor dicho, el lugar de procedencia de la versión, en este caso Tánger (Marruecos). El décimo campo son los archivos que contienen las imágenes.

Sin embargo, el sistema de metadatos Dublin Core entra en conflicto con el sistema de catalogación del Archivo del Romancero en un aspecto muy concreto. A pesar de que consideramos como documento toda pieza de información individual y material, lo cierto es que podemos encontrar documentos duplicados tanto en título como en signatura con metadatos diferentes. Esto se debe a que el Archivo fue concebido como una herramienta de investigación, más que de xxiv).

9. Una descripción precisa de cada uno de estos datos puede encontrarse en Catalán (1998: xix-

10. Concretamente: http:/fundacionramonmenendezpidal.org/archivodigital/items/show/28104.

11. Se trata del Índice General del Romancero, un número asignado a cada tema romancístico para facilitar la identificación. 
acumulación y, por ello, cada detalle de los documentos está descrito de forma precisa; de ahí que el nombre del Catálogo predecesor incluya el término analítico, entendido en su acepción más minuciosa. De este modo, podemos encontrar siete ocurrencias para la signatura A005002-0005. Todas ellas se corresponden con la versión antigua del romance “Cabalga Diego Laínez” transmitida por el Cancionero de Romances de Amberes de 1547-1549 que incluye anotaciones manuscritas de Menéndez Pidal. Sin embargo, cada uno de ellos registra información distinta contenida por el mismo documento. Seremos precisos: la primera ocurrencia registra los datos del documento material original (su lugar de procedencia, su fecha, la edición concreta, entre otros) mientras que el resto se corresponde con la información manuscrita por Menéndez Pidal (concretamente, las variantes de otros testimonios y el material de estudio); la clave para su correcta identificación -al margen de que siempre siga este mismo orden- se encuentra en la información del metadato “Tipo”, donde se precisa si se trata de un original, una fotocopia, variantes, estudio, material de estudio, citas u otros. Esta metodología puede resultar confusa para una persona que se acerca por primera vez a este archivo pero a medida que se vaya familiarizando le resultará de gran ayuda.

No obstante, gracias a la versatilidad del sistema de metadatos Dublin Core, podemos realizar búsquedas que facilitan un acceso más rápido a los documentos que queramos consultar (Figura 9). Concretamente, en la pestaña “Documentos” podemos encontrar dos opciones de búsqueda si abrimos "Buscar documentos”. La primera de ellas es una búsqueda simple o por palabras clave, en la que aparecerán las ocurrencias que contengan en la información de sus metadatos cualquier término buscado. Por ejemplo, si queremos encontrar todas las versiones de romances donde la esposa del Cid, Jimena, tiene un papel protagonista, basta con introducir el término "Jimena” y obtendremos todas las ocurrencias. La segunda de las opciones es una búsqueda avanzada que permite encontrar elementos por intervalos de número de identificación ${ }^{12}$, por colecciones, por tipo ${ }^{13}$ y por cualquiera de los metadatos de elemento (título, descripción, colaborador, localización, entre otros). Por ejemplo, si queremos encontrar todas las versiones recogidas por Manuel Manrique de Lara de los romances de doña Urraca, bastará con introducir el término “Urraca” en el campo “Título” y el término “Manrique” en el campo “Colaborador”.

12. El número de identificación no es la signatura del catálogo sino un número currens que se asigna a cada documento.

13. Las búsquedas por tipo de elemento, por el momento, son ineficaces pues todos los documentos son imágenes. No obstante, serán de gran ayuda cuando en las siguientes fases se añadan los documentos audiovisuales. 


\section{Fundación Ramón MENENDEZ}

\section{BUSCAR ELEMENTOS}

Navegar todo Navegar por Etiqueta Buscar elementos

Búsqueda de palabras clave

Reducir por un campo especifico

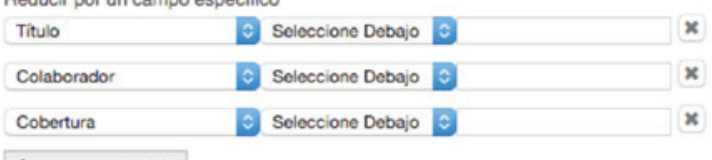

Agregue un campo

Buscar por intervalo de números de ID (ejemplo: 1-4, 156, 79)

Buscar por colección

Seleccione Dobajo

Buscar por tipo

Seloccione Dobajo

Figura 9. Opciones de búsqueda de documentos.

Nos gustaría comentar, por último, dos plugins que hemos instalado en nuestra versión de Omeka y que son un complemento ideal para el Archivo Digital. Se tratan de "Scripto" y "OpenSeaDragon", que, en este caso, funcionan correlativamente (Figura 10). Su implantación nace de una necesidad muy recurrente en la labor filológica: la transcripción del texto. El plugin "Scripto" permite transcribir el documento al mismo tiempo que se visualiza la imagen y con un acceso muy fácil e inmediato a sus metadatos mientras que el plugin "OpenSeaDragon" facilita el aumento o la disminución del tamaño de la imagen para adaptarlo a la mejor visualización con que transcribir. "Scripto" está pensado como un plugin de uso colectivo, mediante el cual los usuarios no solo puedan transcribir la información de cada documento, sino también revisar y editar las transcripciones de otros. Mediante este trabajo colectivo se facilita, por una parte, la lectura de los documentos, a la vez que asegura la precisión de la fidelidad al original; pero, además, por otra parte, facilita la exportación al procesador de textos que estemos utilizando para nuestras investigaciones. Pero Scripto no solo es una fácil 
herramienta para que el investigador pueda transcribir los textos de la forma más cómoda y luego exportarlos a su publicación, sino que se configura además como un motor del trabajo colectivo, pues a partir de las transcripciones de todos, se incorporan nueva información, se implementa el valor de cada documento y se enriquece el contenido del archivo.

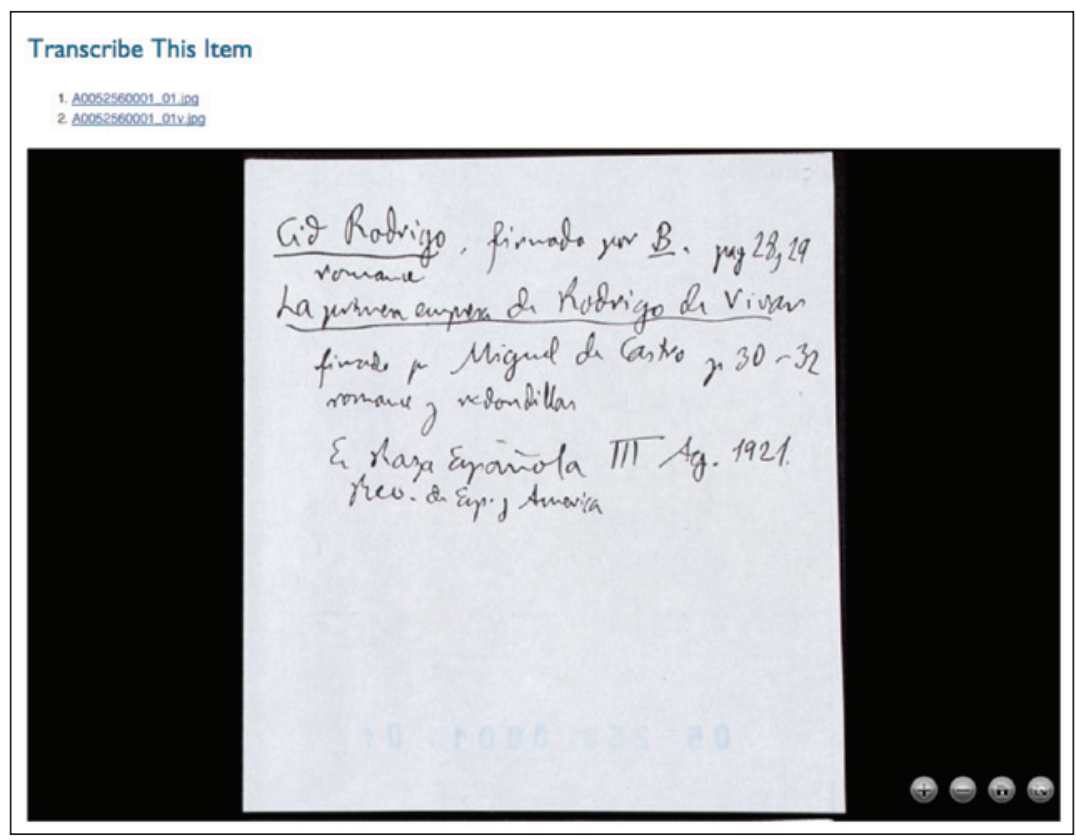

Figura 10. Posibilidad de transcribir el documento mediante Scripto.

Hasta aquí hemos hecho una descripción del funcionamiento del Archivo Digital del Romancero. Probablemente, se hayan percatado, del mismo modo que nosotros somos conscientes -y lo fuimos desde el inicio del proyecto- de su principal debilidad y es que el Archivo Digital no resulta sencillo para una persona que se aproxime sin conocimientos previos. El usuario debe familiarizarse, primero, con el género del romancero -quizá, uno de los géneros más versátiles en parte por su pervivencia a lo largo de siete siglos- y, segundo, con el modelo de catalogación. El Archivo Digital es, sin duda, una utilísima herramienta para el investigador pero, de forma general, puede resultar confuso para un usuario que se acerca, simplemente, con afán de conocer y explorar este patrimonio. Por esta razón, trabajamos, también, en el desarrollo de exposiciones temáticas, que 
puedan acercar los fondos más atractivos del Archivo a un público general ${ }^{14}$. Actualmente, estamos construyendo una exposición en torno a los romances del Cid. Por el momento, se puede contemplar una primera parte relativa a los romances de las mocedades de este héroe ${ }^{15}$. Además de una breve introducción general al conjunto, cada romance tiene una descripción y hemos hecho una selección de los documentos más representativos. De este modo, la inmensidad documental contenida en el Archivo Digital puede seleccionarse, ordenarse y comentarse para facilitar la divulgación entre un público no especializado.

En definitiva, esperamos que en el futuro inmediato podamos migrar más colecciones del Archivo - de hecho ya se está trabajando en la carga de la segunda colección, relativa a los romances épicos e históricos de referente francés- y, a su vez, seguir construyendo exposiciones temáticas. Ahora que el romancero esta casi extinguido de la memoria de nuestros mayores es el momento de proteger todo este patrimonio inmaterial donde han participado miles de personas de una forma u otra, desde los juglares medievales hasta los cantores modernos, desde los impresores del Siglo de Oro hasta los recopiladores de la tradición actual, pasando por editores y estudiosos. En todo este proceso de transmisión de este patrimonio colectivo es donde se sitúa nuestro proyecto. Como un engranaje más de la cadena de trabajo en conjunto, el Archivo Digital pretende configurarse como el preservador de todo este patrimonio pero, al mismo tiempo, pretende ser también una herramienta que pueda funcionar como punto de partida para investigaciones avanzadas en literatura oral y como difusor para el público general de estos fondos de incalculable valor.

\section{Bibliografía}

ALCARAZ MARTÍNEZ, R. (2012). “Omeka: exposicions virtuals i distribució de colleccions digitals”. BiD: Textos universitaris de biblioteconomia i documentació 28: <http://bid.ub.edu/28/alcaraz2.htm>. (Acceso 24 febrero 2016). CATALÁN, D. (2001). El Archivo del Romancero. Patrimonio de la humanidad. Historia documentada de un siglo de historia. Madrid: Fundación Ramón Menéndez Pidal.

14. Un buen análisis sobre los límites y las ventajas de Omeka como gestor de exposiciones virtuales puede encontrarse en Saorín Pérez (2011) o en Alcaraz Martínez (2012).

15. Concretamente puede consultarse en la siguiente dirección: http://fundacionramonmenendezpidal. org/archivodigital/exhibits/show/romancero-del-cid. 
CATALÁN, D. (Coord.) (1998). Catálogo analítico del Archivo romancístico Menéndez Pidal - Goyri. Barcelona: Quaderns crema; Fundación Ramón Menéndez Pidal.

DAUDINOT FOUNIER, I. (2006). "Descripción de los recursos de información en Internet: formato Dublín Core”. Revista Cubana de Información en Ciencias de la Salud 14 (4): <http://bvs.sld.cu/revistas/aci/vol14_4_06/aci09406. htm>. (Acceso 25 febrero 2016).

HEREDIA HERRERA, A. (2007). ¿Qué es un archivo?. Gijón: Ediciones Trea. KUCSMA, J. et al. (2010). "Using Omeka to Build Digital Collections: The METRO Case Study”. D-Lib Magazine 16 (3): <http://www.dlib.org/dlib/ march10/kucsma/03kucsma.html>. (Acceso 24 febrero 2016).

LUCÍA MEGÍAS, J. M. (2010). "De las bibliotecas digitales a las plataformas de conocimiento (notas sobre el futuro del texto en la era digital)" en Estudos de edición crítica e lírica galego-portuguesa. (Coords. M. Arbor Aldea y A. Fernández Guiadanes). Santiago: Universidad de Santiago de Compostela.

SAORÍN PÉREZ, T. (2011). "Exposiciones digitales y reutilización: aplicación del software libre Omeka para la publicación estructurada”. MÉI: Métodos de Información 2 (2): 29-46.

WEIBEL, S. (2010). "Dublin Core Metadata Initiative (DCMI): A personal History" en Encyclopedia of library and information sciences. (Coord. M. J. Bates). Boca Raton: CRC Press.

WEIBEL, S. y WAGNER, H. (2005). "The Dublin Core Metadata Registry: Requirements, Implementation and Experience”. JoDI: Journal of Digital Information 6 (2): 1-20. 